Published in final edited form as:

Nutr Cancer. 2008 ; 60(3): 285-291.

\title{
Dietary patterns and risk of ovarian cancer in the California Teachers Study cohort
}

\author{
Ellen T. Chang ${ }^{1,2}$, Valerie S. Lee ${ }^{1}$, Alison J. Canchola ${ }^{1}$, Tapashi B. Dalvi ${ }^{1}$, Christina A. \\ Clarke $^{1,2}$, Peggy Reynolds ${ }^{1,2}$, David M. Purdie ${ }^{1}$, Daniel O. Stram ${ }^{3}$, Dee W. West ${ }^{1,2}$, Argyrios \\ Ziogas $^{4}$, Leslie Bernstein ${ }^{3}$, and Pamela L. Horn-Ross ${ }^{1,2}$ \\ 1 Northern California Cancer Center, Fremont, California, USA \\ 2Division of Epidemiology, Department of Health Research and Policy, Stanford University School of \\ Medicine, Stanford, California, USA \\ 3Norris Comprehensive Cancer Center, Keck School of Medicine of the University of Southern California, \\ Los Angeles, California, USA \\ 4School of Medicine, University of California, Irvine, California, USA
}

\begin{abstract}
Previous studies have examined the association between individual foods or nutrients, but not overall diet, and ovarian cancer risk. To account for the clustering of foods in the diet, we investigated the association between dietary patterns and risk of ovarian cancer in the prospective California Teachers Study cohort. Of 97,292 eligible women who completed the baseline dietary assessment in 19951996, 311 women developed epithelial ovarian cancer on or before December 31, 2004. Based on principal components analysis, five major dietary patterns were identified and termed "plant-based," "high-protein/high-fat," "high-carbohydrate," "ethnic," and "salad-and-wine." Multivariable Cox proportional hazards regression analysis was used to estimate associations between these dietary patterns and risk of incident ovarian cancer. Most of the dietary patterns were not significantly associated with ovarian cancer risk. However, women who followed a plant-based diet had higher risk; comparing those in the top quintile of plant-based food intake with those in the lowest quintile, the relative risk of ovarian cancer was 1.65 (95\% confidence interval: $1.07-2.54 ; P_{\text {trend }}=0.03$ ). Associations with the five dietary patterns did not vary by known ovarian cancer risk factors or other behavioral or sociodemographic characteristics. Overall, our results show no convincing associations between dietary patterns and ovarian cancer risk.
\end{abstract}

\section{INTRODUCTION}

Indirect evidence, including international incidence variation and changes in risk after migration, suggests that diet may play an etiologic role in ovarian cancer (1). Some previous studies found an inverse association of vegetable and whole grain consumption, and a positive association of meat and fat consumption, with ovarian cancer, suggesting that a typical western diet may increase risk; however, findings are inconsistent (2). To our knowledge, no study has yet examined the association between dietary patterns and risk of ovarian cancer. This approach evaluates overall diet rather than individual foods or nutrients, thereby accounting for the clustering of foods in one's diet, and provides a global assessment of nutrients and other dietary compounds that likely interact when consumed in combination (3). Some nutrients are highly intercorrelated in the diet and therefore difficult to examine separately, and nutrients that are

Corresponding author: Ellen Chang, Northern California Cancer Center, 2201 Walnut Avenue, Suite 300, Fremont, CA 94538, USA; email: ellen@nccc.org. 
commonly associated with certain dietary patterns may be confounded by those patterns (4). We identified five main dietary patterns in the prospective California Teachers Study cohort and investigated the associations of these patterns with ovarian cancer risk.

\section{MATERIALS AND METHODS}

\section{Study population}

The study cohort, described in detail elsewhere (5), comprises 133,479 active and retired female public school teachers and administrators who completed a mailed questionnaire in 1995-1996. For this analysis, we sequentially excluded women who, at baseline, were not California residents $(N=8,867)$, had an unknown history of cancer $(N=662)$, consented to participate only in analyses of breast cancer $(N=18)$, reported having had a bilateral oophorectomy $(N=14,422)$, had a history of ovarian cancer prior to joining the cohort $(N=640)$, were aged 85 years or older $(N=1,874)$, had missing, invalid, or inconsistent data on dietary intake, including supplements $(N=2,949)$, reported very low or high energy intake ( $<600$ or $>5,000 \mathrm{kcals} /$ day; $N=1,585$ and 74 , respectively), or had missing, invalid, or inconsistent data on recent alcohol intake, which contributed to the dietary patterns and estimated total daily caloric intake $(N=5,096)$, leaving 97,292 women for follow-up.

\section{Follow-up}

Cohort members contributed person-days to the analysis from the date of completion of the baseline questionnaire until the date of first diagnosis with borderline or invasive ovarian cancer, relocation out of California, death, or December 31, 2004, whichever occurred earliest. Incident epithelial ovarian cancer (ICD-O-3 site C569, excluding morphology codes 8240$8245,8590-8671$, and 9060-9989 (6)) was identified through linkage with the populationbased California Cancer Registry, which has an estimated statewide coverage of $99 \%$ (7). Relocation out of California and date and cause of death were determined by responses to follow-up questionnaires, notification by participants or their relatives, and various database linkages, as described previously (5). At the end of follow-up, 279 women were diagnosed with invasive epithelial ovarian cancer and 32 with borderline epithelial ovarian cancer.

\section{Principal components analysis of dietary patterns}

Dietary intake during the year before baseline was assessed using a validated food-frequency questionnaire, as previously described (8). To identify common underlying dietary patterns in the overall cohort, based on consumption of 112 foods, beverages (including alcoholic beverages), and supplemental vitamins, we performed a principal components analysis, followed by a varimax orthogonal rotation to maximize interpretability and minimize correlation between components (3). All cohort members under age 85 years who completed the food-frequency questionnaire were included in the principal components analysis. Frequency of consumption of each item was adjusted for portion size and coded as number of medium servings per day. The number of principal components extracted was based on eigenvalues, scree plots, and interpretability. For each dietary pattern, component scores for each participant were calculated using the loadings for all dietary items; the standardized scoring coefficient (the simple correlation matrix multiplied by the component loading matrix) for each item was multiplied by the standardized value of the item for that individual. Thus, all participants had a score for each dietary pattern, with higher scores indicating higher intake of the foods characterizing that pattern. Dietary patterns were labeled based on food items with a high positive loading. 


\section{Statistical analysis}

We used multivariable Cox proportional hazards regression analysis to estimate relative risks (RRs), with 95\% confidence intervals (CIs), for the associations between dietary patterns and ovarian cancer risk, using age (in days) as the time scale. Component scores for each dietary pattern were either categorized into quintiles based on the distribution in the cohort, or analyzed as continuous variables (1-unit change in score) in order to evaluate the linear association with risk. We tested the assumption of proportional hazards for each dietary pattern using significance tests of interactions with the time scale and visual examination of scaled Schoenfeld residual plots (9), and found no violations of the assumption.

Models included all five dietary patterns and were adjusted for race/ethnicity (White or nonWhite) and total daily caloric intake (continuous kilocalories) only, or for race/ethnicity, total daily caloric intake, parity $(0,1-2$, or $\geq 3$ full-term pregnancies), use of oral contraceptives (OC; never, $<5$ years, or $\geq 5$ years), average annual strenuous physical exercise from high school through age 54 years $(<0.5,0.5-3.99$, or $\geq 4$ hours/week), average daily consumption of alcohol from wine in the year before baseline (continuous grams), menopausal status/use of hormone therapy (HT) (premenopausal; peri-/postmenopausal [HT: never, estrogen-only for $\leq 5$ or $>5$ years, combination estrogen-progestin, estrogen-only and estrogen-progestin, or unknown]; unknown menopausal status due to HT use during the menopausal transition [HT: $\leq 5$ years, $>5$ years, or unknown]; or unknown menopausal status due to other reasons), and interaction terms between the time scale and menopausal status/HT use, and were stratified by age at baseline (in years). These covariates were included due to their independent associations with risk of ovarian cancer in the cohort $(10,11)$. Missing values were coded as indicator variables, which were found not to be associated with ovarian cancer risk. Wald tests for trend were computed by including a continuous term for the median score within each quintile; nonlinearity of trends was tested using likelihood ratio tests (12).

To examine whether associations with dietary patterns varied by background risk of ovarian cancer, we classified women according to four behavioral factors associated with increased risk in the cohort: $\leq 2$ (vs. $>2$ ) full-term pregnancies, $0-4$ (vs. $\geq 5$ ) years of OC use, $<4$ (vs. $\geq 4$ ) hours/week of strenuous physical exercise, and ever-use (vs. never-use) of estrogen-only HT. Each combination of these factors was categorized as conferring high $(\mathrm{R} R \approx 2)$, medium $(\mathrm{RR} \approx 1.5)$, or low $(\mathrm{RR} \approx 1)$ background risk based on the strength of its observed association with ovarian cancer risk. For example, women with all four risk factors had nearly twice the ovarian cancer risk of women with none of the four, and were therefore classified as "highrisk." Likelihood ratio tests for heterogeneity were computed using cross-product terms between covariates and dietary pattern in categorical quintiles. All reported $P$-values are twosided. Analyses were performed using SAS Version 9.1 (SAS Institute, Cary, NC).

\section{RESULTS}

The five most prominent dietary patterns identified in the cohort were broadly classified as "plant-based," "high-protein/high-fat," "high-carbohydrate," "ethnic," and "salad-andwine" (Table 1). The plant-based dietary pattern explained $4.7 \%$ of the variance due to diet in the overall cohort, the high-protein/high-fat pattern explained $4.5 \%$, the high-carbohydrate pattern explained $3.3 \%$, the ethnic pattern explained 3.2\%, and the salad-and-wine pattern explained $2.9 \%$. The diet of $35.0 \%$ of the eligible cohort was characterized by a single pattern (defined as having a component score greater than the $75^{\text {th }}$ percentile for only one pattern), while $37.6 \%$ had diets characterized by a combination of patterns; $27.4 \%$ had diets that did not closely correspond to any of the five patterns.

Most dietary patterns were not significantly associated with ovarian cancer risk (Table 2). However, the plant-based diet was positively associated with risk, with a dose-response trend 
toward greater risk with a higher plant-based component score. Women whose component score for the plant-based pattern was above the median were more likely than those with a score below the median to have certain behavioral risk factors for ovarian cancer, including ever-use of estrogen-only HT (20\% vs. $14 \%)$ and use of OCs for less than 5 years $(66 \%$ vs. $59 \%)$. However, they were less likely to have had $\leq 2$ full-term pregnancies $(73 \%$ vs. $79 \%)$ and to consume $\geq 1$ drink/day of wine ( $14 \%$ vs. $21 \%$ ), and were equally likely to have averaged $<4$ hours/week of strenuous exercise $(17 \%)$. The high-carbohydrate diet was also marginally, albeit non-significantly, associated with elevated ovarian cancer risk.

Associations with dietary patterns did not vary significantly by background risk of ovarian cancer, age group at baseline ( $<50$ or $\geq 50$ years), region of residence (San Francisco Bay Area/ southern coastal region or the rest of California (13)), neighborhood socioeconomic status (lower three quartiles or highest quartile statewide (13)), body mass index ( $<30.0$ or $\geq 30.0 \mathrm{~kg}$ / $\mathrm{m}^{2}$ ), supplemental vitamin use (yes or no), or wine intake ( $<1$ or $\geq 1 \mathrm{drink} /$ day), and there were no significant interactions between any two patterns (data not shown). These associations did not change when the analysis was restricted to invasive $(N=279)$ or serous $(N=147)$ ovarian cancer cases, or women who were peri- or post-menopausal at baseline $(N=43,136)$ (data not shown). Likewise, the overall results were unchanged when wine consumption was not separately adjusted for (data not shown).

\section{DISCUSSION}

In this cohort, we observed no statistically significant association between a high-protein/highfat, ethnic, or salad-and-wine dietary pattern and overall ovarian cancer risk, and a suggestive but non-significant positive association with a high-carbohydrate diet. While our results contrast with some studies suggesting that a diet high in meat and fat increases ovarian cancer risk, they are consistent with the majority of studies (2), including ours (11), showing that most individual foods and nutrients are not associated with ovarian cancer risk. We did, however, observe an incongruous finding of increased risk with a plant-based diet.

Given that several large, prospective studies, including ours, detected no association between fruits, vegetables, dietary antioxidants, or other plant components and risk of ovarian cancer (14-20), it is improbable that a plant-based diet directly contributes to ovarian cancer development. Rather, the indication of a positive association between a plant-based dietary pattern and ovarian cancer risk may be due to uncontrolled or residual confounding by factors such as long-term estrogen-only HT use and OC non-use. Likewise, the recently reported positive association between wine intake and ovarian cancer risk in this cohort was attributed to imperfect control for known or unknown confounders, rather than a direct effect of wine (10). However, a dietary pattern characterized by salad and wine intake was not associated with ovarian cancer risk in the present analysis, even when wine intake was not controlled for separately.

Besides potential confounding, other limitations of our study should be considered. The five major dietary patterns were extracted and labeled based in part on subjective decisions, and explained only $18.9 \%$ of the variance in diet in the cohort. The low proportion of variance explained likely reflects the complexity and variability of individuals' diets, as well as our prioritization of interpretability, rather than variance explained, when extracting a limited number of patterns (21). Another limitation is that we assessed dietary patterns only at baseline, and were therefore unable to capture changes over time. However, dietary patterns in adulthood tend to be fairly well correlated from year to year (22), and future follow-up with repeated dietary assessments in the cohort will enable us to examine associations with dietary changes and cumulative dietary intake. In addition, some stratified estimates of association were based on a limited number of cases, and the total number of cases was not very large. Finally, the 
cohort may not be representative of the source population of all female school teachers and administrators in California, nor the general population of all women.

These limitations are offset by several strengths of the study, including its detailed exposure information, prospective design, and virtually complete ascertainment of cancer outcomes. In addition, the analytic approach takes advantage of the collinearity of foods and nutrients consumed in combination. Despite our inability to capture all dietary patterns in the cohort, foods grouped into patterns more closely resemble dietary habits than do foods considered in isolation.

In conclusion, we did not observe evidence of clear associations between dietary patterns and ovarian cancer risk. The increased risk among women following a plant-based dietary pattern is likely explained by other ovarian cancer risk factors that are correlated with dietary intake. Our findings do not exclude the possibility that other dietary patterns that are prevalent in distinct populations may influence ovarian cancer risk. For instance, it is conceivable that in some populations (e.g., much of East Asia) where a heavily soy-based diet is prevalent, such a diet may decrease risk of ovarian cancer through a protective effect of isoflavones or other components of soy (11). In the present cohort, however, race and birthplace were not associated with ovarian cancer risk, and there were too few non-U.S.-born cases for robust stratified analyses. Together with null results from several multi-center and pooled prospective studies of diet and ovarian cancer (17-19,23-25), our overall results suggest that diet does not play a major etiologic role in ovarian cancer.

\section{ACKNOWLEDGMENTS}

The authors would like to thank the CTS Steering Committee members who are responsible for the formation and maintenance of the cohort within which this study was conducted, but who are not authors of the current paper: Hoda Anton-Culver, Rosemary Cress, Dennis Deapen, Susan Neuhausen, Rich Pinder, and Giske Ursin.

This research was supported by grants R03 CA113024 and R01 CA77398 from the National Cancer Institute, contract 97-10500 from the California Breast Cancer Research fund, and the California Breast Cancer Act of 1993, California Department of Health Services. The funding sources did not contribute to the design or conduct of the study, nor to the writing or submission of this manuscript. The collection of cancer incidence data used in this study was supported by the California Department of Health Services as part of the statewide cancer reporting program mandated by California Health and Safety Code Section 103885; the National Cancer Institute's Surveillance, Epidemiology and End Results Program under contract N01-PC-35136 awarded to the Northern California Cancer Center, contract N01PC-35139 awarded to the University of Southern California, and contract N02-PC-15105 awarded to the Public Health Institute; and the Centers for Disease Control and Prevention's National Program of Cancer Registries, under agreement \#U55/CCR921930-02 awarded to the Public Health Institute. The ideas and opinions expressed herein are those of the authors and endorsement by the State of California, Department of Health Services, the National Cancer Institute, and the Centers for Disease Control and Prevention or their contractors and subcontractors is not intended nor should be inferred.

\section{REFERENCES}

1. Henderson MM. International differences in diet and cancer incidence. J Natl Cancer Inst Monogr 1992:59-63. [PubMed: 1616812]

2. Schulz M, Lahmann PH, Riboli E, Boeing H. Dietary determinants of epithelial ovarian cancer: a review of the epidemiologic literature. Nutr Cancer 2004;50:120-140. [PubMed: 15623459]

3. Hu FB. Dietary pattern analysis: a new direction in nutritional epidemiology. Curr Opin Lipidol 2002;13:3-9. [PubMed: 11790957]

4. Randall E, Marshall J, Graham S, Brasure J. Frequency of food use data and the multidimensionality of diet. J Am Diet Assoc 1989;89:1070-1075. [PubMed: 2547859]

5. Bernstein L, Allen M, Anton-Culver H, Deapen D, Horn-Ross PL, et al. High breast cancer incidence rates among California teachers: results from the California Teachers Study (United States). Cancer Causes Control 2002;13:625-635. [PubMed: 12296510] 
6. Chen VW, Ruiz B, Killeen JL, Cote TR, Wu XC, Correa CN. Pathology and classification of ovarian tumors. Cancer 2003;97:2631-2642. [PubMed: 12733128]

7. Kwong, SL.; Perkins, CI.; Morris, CR.; Cohen, R.; Allen, M.; Wright, WE. California Department of Health Services. Sacramento, CA: Cancer Surveillance Section; 2001. Cancer in California: 19881999.

8. Horn-Ross PL, Hoggatt KJ, West DW, Krone MR, Stewart SL, et al. Recent diet and breast cancer risk: the California Teachers Study (USA). Cancer Causes Control 2002;13:407-415. [PubMed: 12146845]

9. Hosmer, DW., Jr; Lemeshow, S. Regression Modeling of Time to Event Data. New York: John Wiley \& Sons, Inc.; 1999. Applied Survival Analysis.

10. Chang ET, Canchola AJ, Lee VS, Clarke CA, Purdie DM, et al. Wine and other alcohol consumption and risk of ovarian cancer in the California Teachers Study cohort. Cancer Causes Control 2007;18:91-103. [PubMed: 17186425]

11. Chang ET, Lee VS, Canchola AJ, Clarke CA, Purdie DM, et al. Diet and risk of ovarian cancer in the California Teachers Study cohort. Am. J. Epidemiol 2007;165:802-813. [PubMed: 17210953]

12. Breslow, NE.; Day, NE. Volume 2 - The Design and Analysis of Cohort Studies. Lyon: International Agency for Research on Cancer; 1987. Statistical Methods in Cancer Research.

13. Reynolds P, Hurley S, Goldberg DE, Anton-Culver H, Bernstein L, et al. Regional variations in breast cancer among California teachers. Epidemiology 2004;15:746-754. [PubMed: 15475725]

14. Fairfield KM, Hankinson SE, Rosner BA, Hunter DJ, Colditz GA, Willett WC. Risk of ovarian carcinoma and consumption of vitamins $\mathrm{A}, \mathrm{C}$, and $\mathrm{E}$ and specific carotenoids: a prospective analysis. Cancer 2001;92:2318-2326. [PubMed: 11745286]

15. Bertone ER, Rosner B, Hunter D, Stampfer MJ, Speizer FE, et al. Dietary fat intake and ovarian cancer in a cohort of US women. Am J Epidemiol 2002;156:22-31. [PubMed: 12076885]

16. Larsson SC, Holmberg L, Wolk A. Fruit and vegetable consumption in relation to ovarian cancer incidence: the Swedish Mammography Cohort. Br J Cancer 2004;90:2167-2170. [PubMed: 15150575]

17. Schulz M, Lahmann PH, Boeing H, Hoffmann K, Allen N, et al. Fruit and vegetable consumption and risk of epithelial ovarian cancer: the European Prospective Investigation into Cancer and Nutrition. Cancer Epidemiol Biomarkers Prev 2005;14:2531-2535. [PubMed: 16284374]

18. Koushik A, Hunter DJ, Spiegelman D, Anderson KE, Arslan AA, et al. Fruits and vegetables and ovarian cancer risk in a pooled analysis of 12 cohort studies. Cancer Epidemiol Biomarkers Prev 2005;14:2160-2167. [PubMed: 16172226]

19. Koushik A, Hunter DJ, Spiegelman D, Anderson KE, Buring JE, et al. Intake of the major carotenoids and the risk of epithelial ovarian cancer in a pooled analysis of 10 cohort studies. Int $\mathrm{J}$ Cancer 2006;119:2148-2154. [PubMed: 16823847]

20. Navarro, Silvera SA.; Jain, M.; Howe, GR.; Miller, AB.; Rohan, TE. Carotenoid, vitamin A, vitamin $\mathrm{C}$, and vitamin $\mathrm{E}$ Intake and risk of ovarian cancer: a prospective cohort study. Cancer Epidemiol Biomarkers Prev 2006;15:395-397. [PubMed: 16492935]

21. McCann SE, Moysich KB, Mettlin C. Intakes of selected nutrients and food groups and risk of ovarian cancer. Nutr Cancer 2001;39:19-28. [PubMed: 11588898]

22. Willett, W. Nutritional Epidemiology. 2nd Ed.. New York: Oxford University Press; 1998.

23. Genkinger JM, Hunter DJ, Spiegelman D, Anderson KE, Beeson WL, et al. A pooled analysis of 12 cohort studies of dietary fat, cholesterol and egg intake and ovarian cancer. Cancer Causes Control 2006;17:273-285. [PubMed: 16489535]

24. Genkinger JM, Hunter DJ, Spiegelman D, Anderson KE, Arslan A, et al. Dairy products and ovarian cancer: a pooled analysis of 12 cohort studies. Cancer Epidemiol Biomarkers Prev 2006;15:364-372. [PubMed: 16492930]

25. Schulz M, Nothlings U, Allen N, Onland-Moret NC, Agnoli C, et al. No Association of Consumption of Animal Foods with Risk of Ovarian Cancer. Cancer Epidemiol Biomarkers Prev 2007;16:852855. [PubMed: 17416784] 
Table 1

Component matrix for the major dietary patterns identified in the California Teachers Study cohort; food items with loading $\geq|0.30|$ are shown

\begin{tabular}{llll}
\hline Food item & $\begin{array}{l}\text { Plant- } \\
\text { based }\end{array}$ & $\begin{array}{l}\text { High- } \\
\text { protein/ } \\
\text { high-fat }\end{array}$ & $\begin{array}{l}\text { High- } \\
\text { carbohydrate }\end{array}$
\end{tabular}$\quad \begin{aligned} & \text { Salad- } \\
& \text { and-wine }\end{aligned}$

Peaches, apricots (fresh)

Strawberries, other berries $\quad 0.55$

Carrots, mixed vegetables with carrots $\quad 0.52$

Apples, applesauce 0.5

Other fruit (e.g., raisins, grapes, fruit cocktail, $\quad 0.50$

kiwi, mangoes)

Oranges

Bananas $\quad 0.45$

Watermelon $\quad 0.44$

Cantaloupe 0.4

Other vegetables (e.g., cooked onions, $\quad 0.39$

summer squash)

String beans, green beans $\quad 0.38$

Cauliflower, brussels sprouts $\quad 0.36$

Peaches, apricots (canned, dried) $\quad 0.35$

0.3

Cabbage, cole slaw 0.31

Butter, margarine, other fat added to $\quad 0.55$

vegetables or potatoes

Beef roasts, steaks, sandwiches $\quad 0.52$

Sausage, bacon $\quad 0.49$

$\begin{array}{ll}\text { Pork chops, roasts } & 0.46\end{array}$

Hamburgers, cheeseburgers $\quad 0.45$

Beef stews, pot pies with vegetables $\quad 0.43$

Eggs

Fried potatoes, french fries

Butter on bread or rolls

Salad dressing, mayonnaise - regular-fat $\quad 0.38$

Margarine on bread or rolls $\quad 0.34$

Ice cream - regular-fat

Cheese, cheese spread - regular-fat $\quad 0.33$

Hot dogs

Potatoes (boiled, baked, mashed)

Burritos, tacos with meat or beans

Pizza

Salsa, ketchup, taco sauce

Tortillas

Spaghetti, lasagna, other pasta with tomato

sauce

Bagels, English muffins, hamburger buns

Salty snacks (e.g., potato chips, corn chips,

popcorn, crackers)

Cheese, cheese spread - low-fat

Cheese dishes without tomato sauce (e.g.,

macaroni and cheese)

Lentil, pea, or bean soup

Beans (e.g., baked beans, pinto, kidney, not

in soup)

Tofu, bean curd

Vegetable soup (e.g., tomato soup, vegetable

beef soup)

Rice, dishes with rice

Meat substitutes made from soy

Mustard greens, turnip greens, collards

Sweet potatoes, yams

Chili with beans (with or without meat)

Green salad

Fish (broiled, baked)

Wine, champagne

0.36

Salad dressing, mayonnaise - low-fat

Coffee, tea

Tomatoes, tomato juice

Chicken, turkey (roasted, broiled, on

sandwiches)

Shellfish 


\begin{tabular}{llllll}
\hline Food item & $\begin{array}{l}\text { Plant- } \\
\text { based }\end{array}$ & $\begin{array}{l}\text { High- } \\
\text { protein/ } \\
\text { high-fat }\end{array}$ & $\begin{array}{l}\text { High- } \\
\text { carbohydrate }\end{array}$ & Ethnic & $\begin{array}{l}\text { Salad- } \\
\text { and-wine }\end{array}$ \\
\hline
\end{tabular}




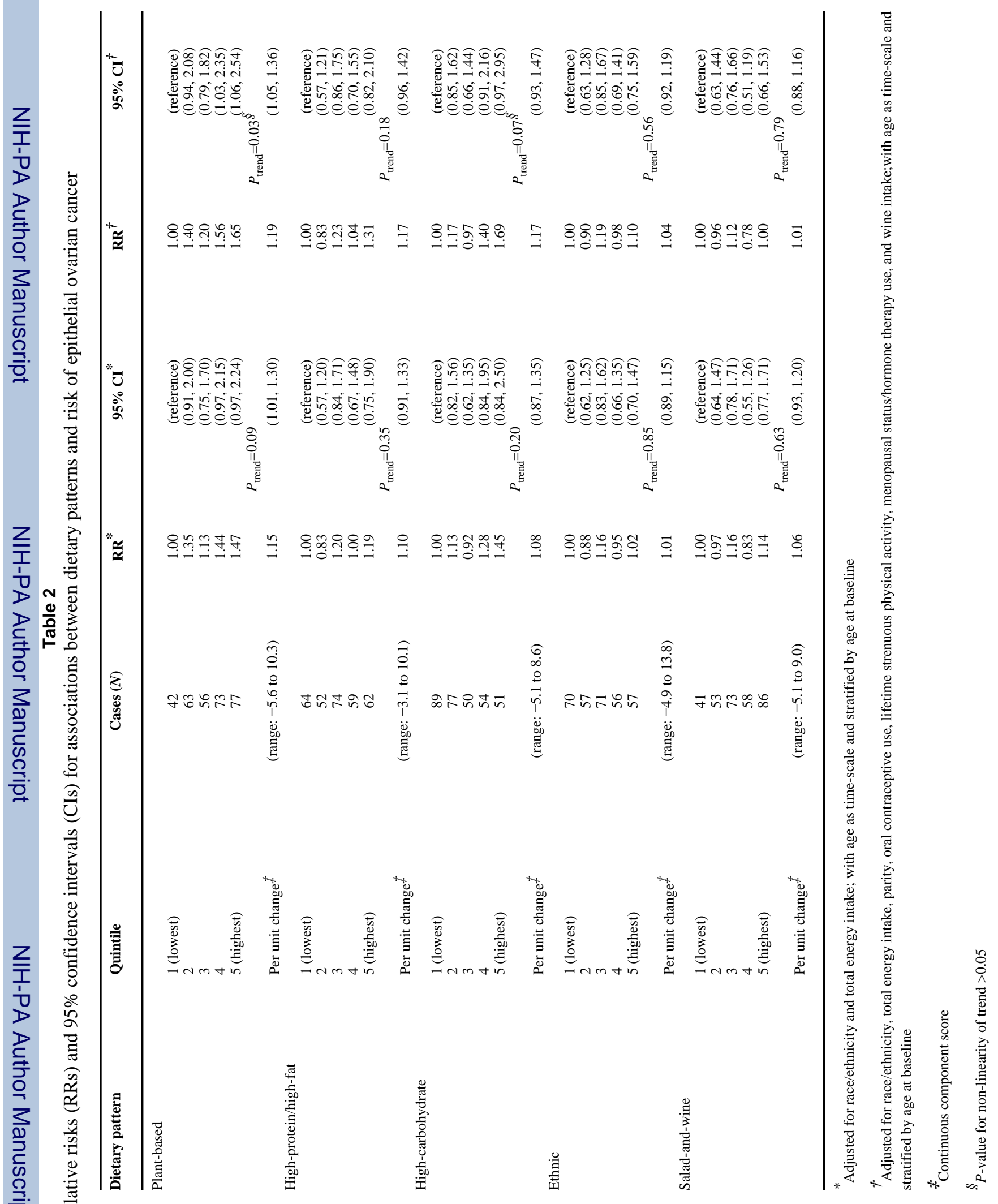

